Canadian

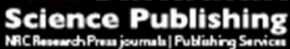

Canadian Geotechnical Journal Revue canadienne de géotechnique

\title{
Centrifuge modelling of an instrumented free-fall sphere for measurement of undrained strength in fine-grained soils
}

\begin{tabular}{|r|l|}
\hline Journal: & Canadian Geotechnical Journal \\
\hline Manuscript ID & cgj-2015-0242.R1 \\
\hline Danuscript Type: & Article \\
\hline Complete List of Authors: & $\begin{array}{l}\text { Morton, John; University of Western Australia, School of Civil and Resource } \\
\text { O'Loughlin, Conleth; University of Western Australia, } \\
\text { White, David; University of Western Australia, Centre for Offshore } \\
\text { Foundation Systems }\end{array}$ \\
\hline Keyword: & Free-falling penetrometer, Sphere, soil strength , fluid drag, clay \\
\hline & \multicolumn{2}{|c}{} \\
\hline
\end{tabular}


Centrifuge modelling of an instrumented free-fall sphere for measurement of undrained strength in fine-grained soils

J.P Morton ${ }^{1}$, C.D O’Loughlin ${ }^{2}$ and D.J White ${ }^{3}$

Words: 5100 (main body) Figures: 12 Equations: $13 \quad$ References: 36.

${ }^{1}$ Corresponding Author,

PhD Candidate, Centre for Offshore Foundation Systems

The University of Western Australia

35 Stirling Highway, Crawley WA 6009, Perth, Australia

Phone: +61 864883974

Fax: +61 864881044

E-mail: john.morton@research.uwa.edu.au

${ }^{2}$ Associate Professor, Centre for Offshore Foundation Systems

The University of Western Australia

35 Stirling Highway, Crawley WA 6009, Perth, Australia

Phone: +61 864887326

Fax: +61 864881044

E-mail: conleth.oloughlin@uwa.edu.au

${ }^{3}$ Professor, Centre for Offshore Foundation Systems

The University of Western Australia

35 Stirling Highway, Crawley WA 6009, Perth, Australia

Phone: +61 864883086

Fax: +61 864881044

E-mail: david.white@uwa.edu.au 


\begin{abstract}
This paper describes centrifuge tests in which a model free-fall sphere was allowed to freefall in water before dynamically embedding within reconstituted samples of kaolin clay and two offshore natural clays. Instrumentation within the sphere measured accelerations along three orthogonal axes. The resultant acceleration was used to calculate sphere velocities and displacements. This allowed the penetration resistance acting on the sphere to be expressed in terms of a single capacity factor that captures soil resistance from both shearing and drag, and varies uniquely with the non-Newtonian Reynolds number. Undrained shear strength profiles obtained from a simple inverse analysis of the acceleration data show good agreement with those obtained using conventional push-in penetrometer tests.
\end{abstract}

\title{
Keywords:
}

Sphere, clay, free-fall, dynamic, fluid drag, physical modelling, soil strength 


\section{Introduction}

Assessments of seabed strength for design are often based on interpretations of the penetration resistance of a cone, T-bar or ball penetrometer as it is pushed into the soil. However, this type of test requires a large seabed frame to provide reaction forces to advance the penetrometer. A more cost effective alternative is to allow a penetrometer to free-fall through the water column, so that the total energy of the penetrometer at the seabed mudline provides the force to drive it into the seabed. Experience with such systems has typically been with slender, shafted projectiles with a conical tip (i.e. similar to a cone penetrometer). In some cases these devices have flukes near the rear of the penetrometer for stability during free-fall (e.g. see Figure 1). Although the ease and speed of installation make free-fall penetrometers an attractive option, their adoption is hampered by difficulties in interpreting soil strength at the very high strain rates that are prevalent during the dynamic penetration. These strain rates are up to eight orders of magnitude higher than in a standard laboratory element test. Hydrodynamic aspects further complicate the analysis. These include drag resistance that not only occurs during free-fall in water, but also during dynamic embedment in soil, and the potential for water to become entrained at the projectile-soil interface. The entrainment of water has been indicated in numerical studies (Sabetamal et al. 2014) and free-fall penetrometer and anchor field tests (Seifert et al. 2008; Jeanjean et al. 2012). These complexities present challenges for free-falling penetrometers in firstly, isolating a value of 'dynamic strength' from the total resistance experienced by the projectile during embedment and secondly, scaling this dynamic strength to a 'static' value appropriate for design.

In soft fine-grained soils, as an alternative to a free-falling CPT, a spherical free-fall penetrometer can be used, of the form shown in Figure 2 (Morton and O'Loughlin 2012; Morton et al. 2015). A spherical free-fall penetrometer is attractive as it benefits from the 
advantages of full-flow penetrometers, which have more tightly bracketed bearing capacity factors for deriving the undrained shear strength, $s_{u}$, from the net penetration resistance (Chung and Randolph 2004). In the context of free-fall penetrometers, the analysis for a sphere is simpler than for a cone as it does not include the somewhat complicated frictional resistance that occurs along the shaft of a cone penetrometer. This resistance is uncertain because it may be affected by water entrainment (Richardson et al. 2009; Jeanjean et al. 2012) and has been shown to exhibit different strain-rate dependency compared to the tip (Dayal et al. 1975; Steiner et al. 2014; Chow et al. 2014)." Finally, unlike a cone penetrometer, a sphere may freely rotate without affecting the projected area and in turn the mobilised shear resistance.
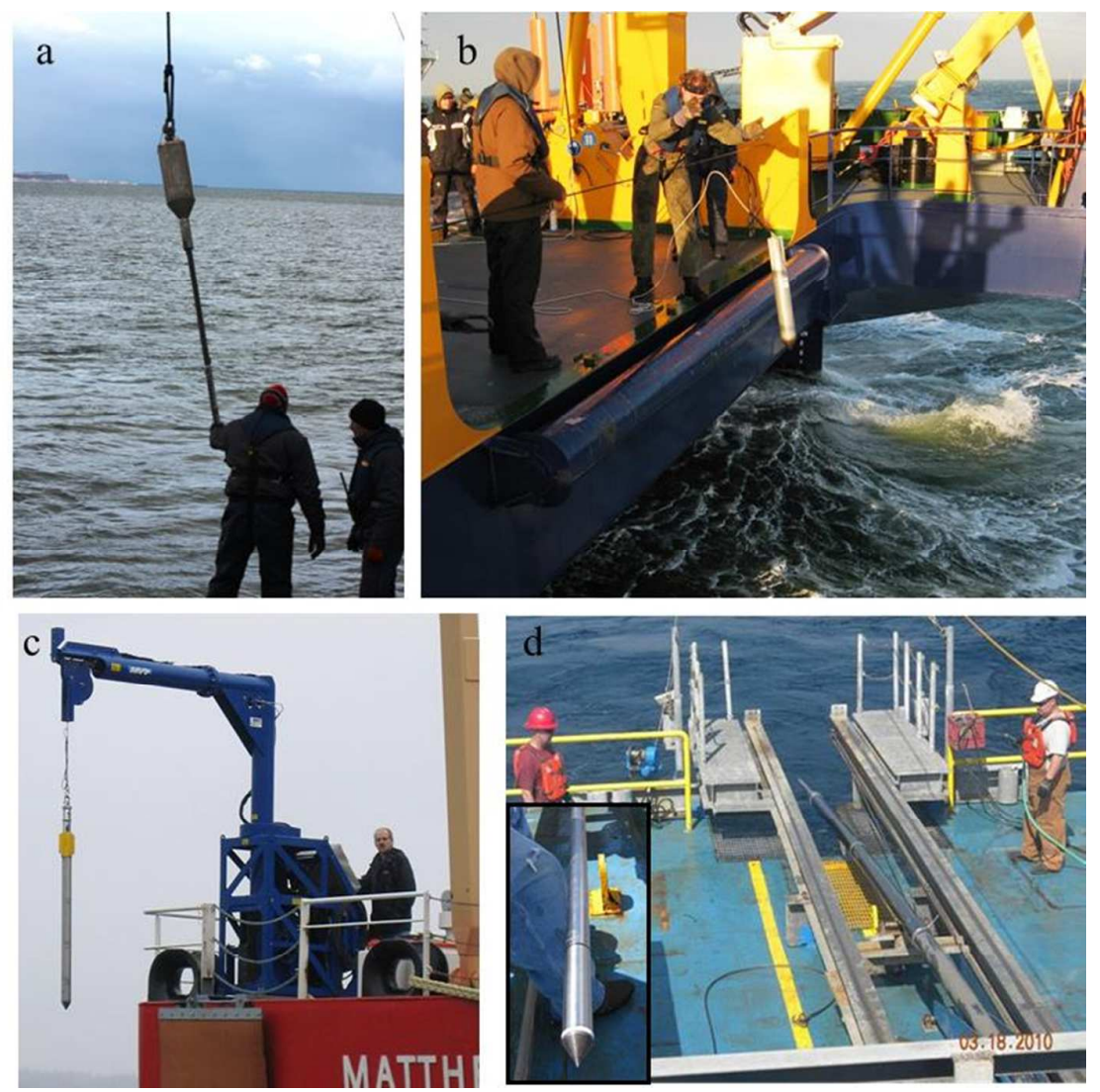

Figure 1. Examples of free-fall shafted penetrometers with conical tips:(a) CPT-Lance (courtesy of Dr. Nina Stark); (b) Nimrod (courtesy of Dr. Nina Stark); (c) FFCPT (Furlong et al. 2006); (d) CPT Stinger (after Young et al. 2011) 


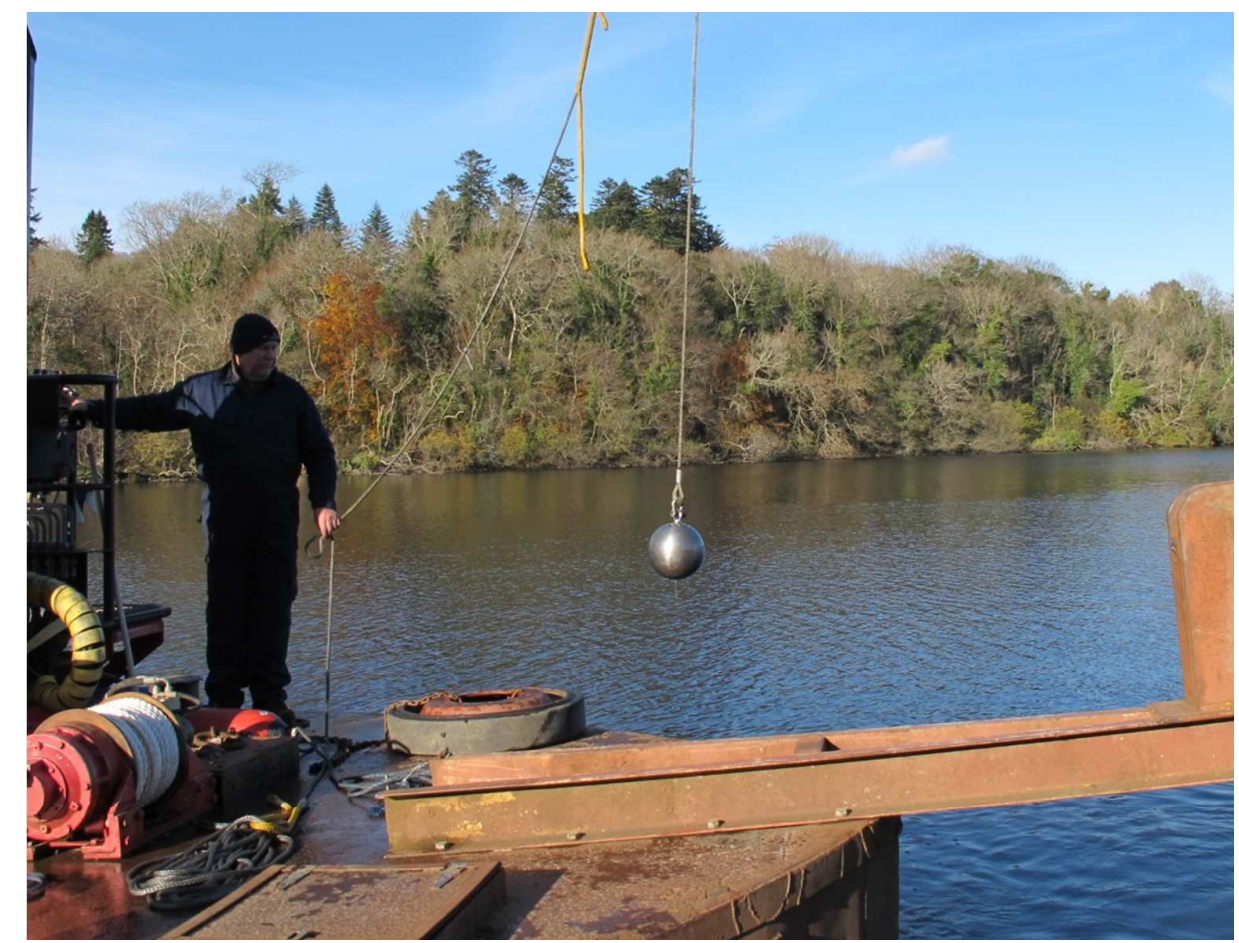

Figure 2. Free-fall sphere ready for release

This paper examines the merit of a free-falling sphere to quantify near surface soil strength using centrifuge data from instrumented free-fall sphere tests in three different clays. A simple inverse analysis of the free-fall data - using a model that couples the drag and strain rate-enhanced shear resistance in terms of a single capacity factor framework - provides profiles of $s_{u}$ with depth that are compared with equivalent profiles obtained from push-in ball penetrometer tests. 


\section{Penetration of a sphere in soil}

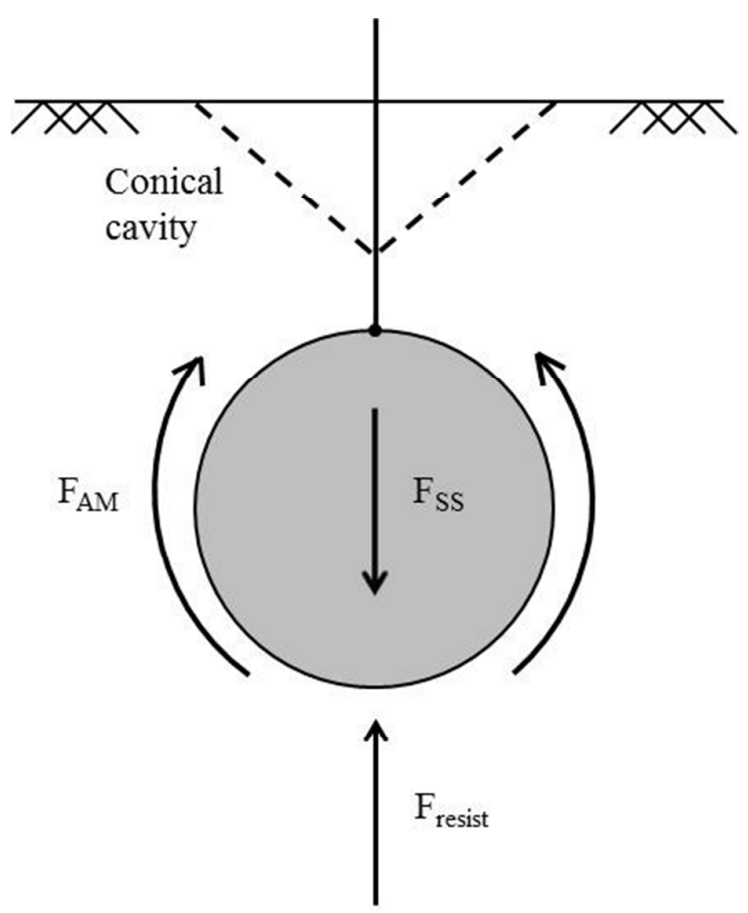

Figure 3: Forces acting on the sphere during penetration in soil

The forces acting on the sphere during penetration in soil (i.e. after it impacts the mudline) are shown schematically in Figure 3, which leads to the following equation that governs the motion response in soil:

$\mathrm{ma}=F_{S S}-F_{A M}-F_{\text {resist }}$

where $\mathrm{a}$ is the linear acceleration ( $\mathrm{v}$ is velocity and $\mathrm{t}$ is time), $\mathrm{m}$ is the mass of the sphere, $\mathrm{F}_{\mathrm{SS}}$ is the submerged weight in soil. This is calculated as the dry weight of the sphere minus the product of the soil unit weight, $\gamma$, and the volume of displaced soil, $\mathrm{V}_{\text {disp. }}$. This volume is that embedded in the soil, with an adjustment for any cavity that is currently growing in the wake of the advancing sphere (Morton et al. 2014). $\mathrm{F}_{\mathrm{AM}}$ is the added mass force, $\mathrm{F}_{\mathrm{AM}}=\mathrm{aC}_{\mathrm{m}} \mathrm{m}_{\text {soil, }}$, 
that occurs during non-stable flows when an object is accelerating or decelerating (Lamb, 1932). The added mass $\left(\mathrm{C}_{\mathrm{m}} \mathrm{m}_{\text {soil }}\right)$ can be interpreted as the mass of surrounding soil that is accelerated with the sphere, which results in a force controlled by the added mass coefficient $\left(\mathrm{C}_{\mathrm{m}}\right)$. The final term on the right hand side of Equation 1 is a combined dynamic resistance force acting on the sphere. $F_{\text {resist }}$ is conventionally considered as the sum of the strain-rate enhanced bearing resistance, $F_{S_{u-o p}}$, and the drag resistance, $\mathrm{F}_{\mathrm{D}}$ :

$\mathrm{F}_{\text {resist }}=F_{S_{u-o p}}+F_{D}=N_{c} S_{u-o p} A_{p}+\frac{1}{2} C_{D} \rho A_{p} v^{2}$

where $\mathrm{N}_{\mathrm{c}}$ is a bearing capacity factor, $\mathrm{A}_{\mathrm{p}}$ is the projected area of the sphere, $\mathrm{s}_{\mathrm{u}-\mathrm{op}}$ is the mobilised, or operative shear strength at the strain rate relevant to the velocity $v, C_{D}$ is an drag coefficient and $\rho$ is the density of the soil. However, Sadhi et al. (2014) and Morton et al. (2015) showed that these terms can be combined via a superposition approach in which the strength and drag resistance components are expressed as a single resistance force:

$\mathrm{F}_{\text {resist }}=\mathrm{Ns}_{\mathrm{u}-\mathrm{op}} A_{p}$

where $\mathrm{N}$ is a geometry-dependant capacity factor that is dependent on the non-Newtonian Reynolds number, $\mathrm{Re}_{\text {non-Newtonian, }}$ (Zakeri et al. 2008):

$\operatorname{Re}_{\text {non-Newtonian }}=\frac{\rho v^{2}}{s_{\mathrm{u}-\mathrm{op}}}$

The well know influence of strain rate, $\dot{\gamma}$, on the mobilised strength due to viscous effects is described by a power law enhancement of the soil strength (Briaud et al. 1984; Biscontin and Pestana 2001; Peuchen and Mayne 2007; Jeong et al. 2009; Lehane et al. 2009; O’Loughlin et al. 2013):

$\mathrm{s}_{\mathrm{u}-\mathrm{op}}=\mathrm{s}_{\mathrm{u}, \mathrm{ref}}\left(\frac{\dot{\gamma}}{\dot{\gamma}_{\text {ref }}}\right)^{\beta}$

where $s_{u, \text { ref }}$ is the undrained shear strength at the reference strain rate $\dot{\gamma}_{\text {ref }}$ and $\beta$ is a strain rate parameter defining the strength of the rate effect for any given soil. As shown by Lehane et 
al. 2009, O'Loughlin et al. (2013) and Chow et al. (2014), the operational shear strain rate around a penetrometer may be approximated by v/D, such that Equation 5 may be written as

$\mathrm{s}_{\mathrm{u}-\mathrm{op}}=\mathrm{s}_{\mathrm{u}, \mathrm{ref}}\left(\frac{v / D}{(v / D)_{\text {ref }}}\right)^{\beta}$

It follows from Equations 2, 3 and 4 that a relationship between $\mathrm{N}$ and $\mathrm{Re}_{\text {non-Newtonian }}$ may then be expressed as:

$\mathrm{N}=\frac{1}{2} \mathrm{C}_{\mathrm{D}} \mathrm{Re}_{\text {non-Newtonian }}+\mathrm{N}_{\mathrm{C}}$

Morton et al. (2015) showed that this framework is capable of describing the resistance acting on a sphere as measured in field tests with an instrumented free-fall sphere. The model requires three main input parameters: the drag coefficient, $C_{D}$, for the sphere over the range of non-Newtonian Reynolds numbers applicable to dynamic penetration in soil, the strain rate parameter, $\beta$, and a reference strain rate, $\dot{\gamma}_{\text {ref. }}$ The selection of these parameters are considered later in the paper.

Equation 7 also requires an assessment of the bearing capacity factor, $\mathrm{N}_{\mathrm{c}}$, and its evolution with depth, as for 'push-in' penetrometer tests such as the CPT, T-bar or ball. Hossain et al. (2005), White et al. (2010), Tho et al. (2012) and Morton et al. (2014) showed that this evolution depends on the dimensionless soil strength ratio, $\mathrm{s}_{\mathrm{u}} / \gamma^{\prime} \mathrm{D}$, where $\gamma^{\prime}$ is the effective unit weight of the soil and $\mathrm{D}$ is the diameter of the penetrating body. The transition from a reduced $\mathrm{N}_{\mathrm{c}}$ value at shallow penetration where the failure mechanism extends to the soil surface, to the limiting value for deep embedment associated with a full-flow mechanism, has recently been investigated for a sphere in kaolin clay over a wide range of $s_{u} / \gamma^{\prime} D$ (Morton et al. 2014). This approach, expressed by the following power function, has also been shown to work well in two other natural soils (Morton et al. 2015)

$\mathrm{N}_{\mathrm{c}}=\mathrm{N}_{\mathrm{b}-\text { deep }}\left(\frac{\widehat{\mathrm{w}}_{\mathrm{op}}}{\widehat{\mathrm{w}}_{\text {deep-op }}}\right)^{\mathrm{p}}$

where the transitional depth at which $\mathrm{N}_{\mathrm{c}}=\mathrm{N}_{\mathrm{c} \text {-deep }}$ is given by 
$\widehat{\mathrm{w}}_{\text {deep-op }}=\mathrm{a}+\left(\mathrm{b} \frac{\mathrm{s}_{\mathrm{u}}}{\gamma^{\prime \mathrm{D}}}\right)^{\mathrm{c}}+\frac{\mathrm{d}-\mathrm{a}}{1+\left[\left(\mathrm{s}_{\mathrm{u}} / \gamma^{\prime D}\right) / \mathrm{e}\right]^{\mathrm{f}}}$

and the fitting constants $\mathrm{a}=16.3, \mathrm{~b}=0.12, \mathrm{c}=1.3, \mathrm{~d}=0.52, \mathrm{e}=4.9, \mathrm{f}=1.5$ and $\mathrm{p}=0.49$.

The above framework may be used with vertical acceleration data, measured during free-fall sphere tests, to obtain undrained shear strength profiles. Rearranging Equation 1, enables Su to be calculated at any depth during penetration from

$$
s_{u}=\frac{F_{S S}-\mathrm{a}\left(\mathrm{m}+\mathrm{C}_{\mathrm{m}} \mathrm{m}_{\text {soil }}\right)}{N \mathrm{~A}_{p}\left[\frac{\mathrm{v} / \mathrm{D}}{(v / D)_{\text {ref }}}\right]^{\beta}}
$$

The merit of Equation 10 in quantifying $s_{u}$ is considered in the remainder of the paper, through consideration of instrumented free-fall sphere centrifuge tests in kaolin clay, Laminaria clay (from the Timor Sea, Erbrich and Hefer 2002) and West Africa clay (from the Gulf of Angola).

\section{Experimental Details}

\section{Measurement technique}

Estimation of $s_{u}$ from free-fall sphere tests requires measurements of the acceleration in the direction of motion. In equivalent field experiments reported by Morton and O'Loughlin (2012), O’Loughlin et al. (2014) and Morton et al. (2015), an inertial measurement unit (IMU) measured acceleration along three orthogonal axes and rotation rates about the same three axes. Interpretation of the IMU data (Blake et al. 2015) required that the measurements were considered within a fixed frame of reference to establish the projectile velocity and displacement along the projectile's direction of motion. This approach becomes complex in a centrifuge environment as the gyroscope-measured rotation rates include a component of the centrifuge rotation rate. However, if the direction of motion can be maintained vertical, the interpretation can be reduced to considering the acceleration along the depth (vertical) axis of a fixed reference frame. This was achieved in the centrifuge tests by allowing the sphere to 
drop through a vertical installation guide located above the soil surface. The acceleration along the vertical direction of motion can then be determined from the resultant acceleration calculated from the acceleration components measured along the three orthogonal axes shown in Figure 4a using a tri-axis accelerometer.

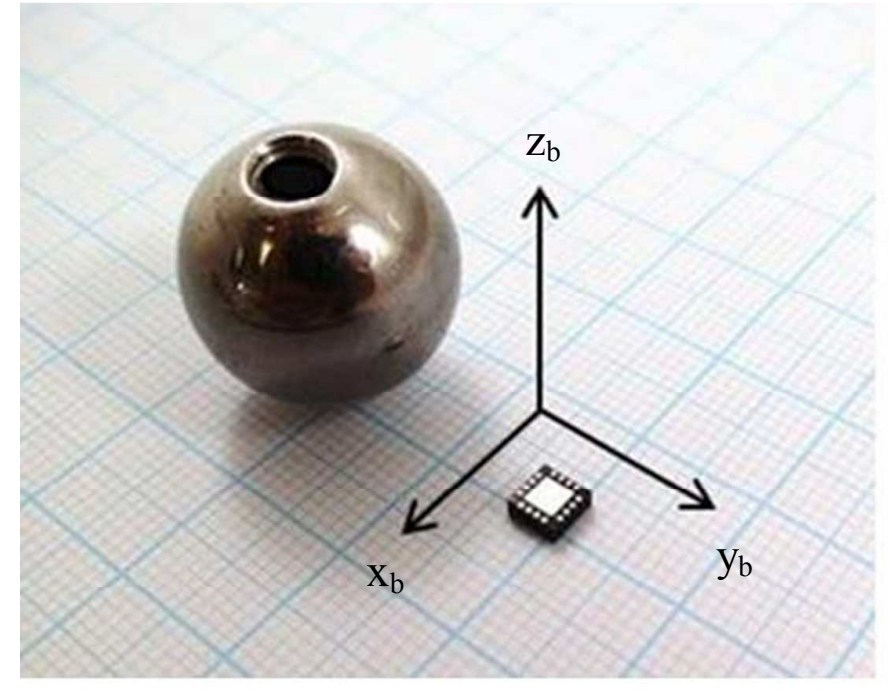

(a)

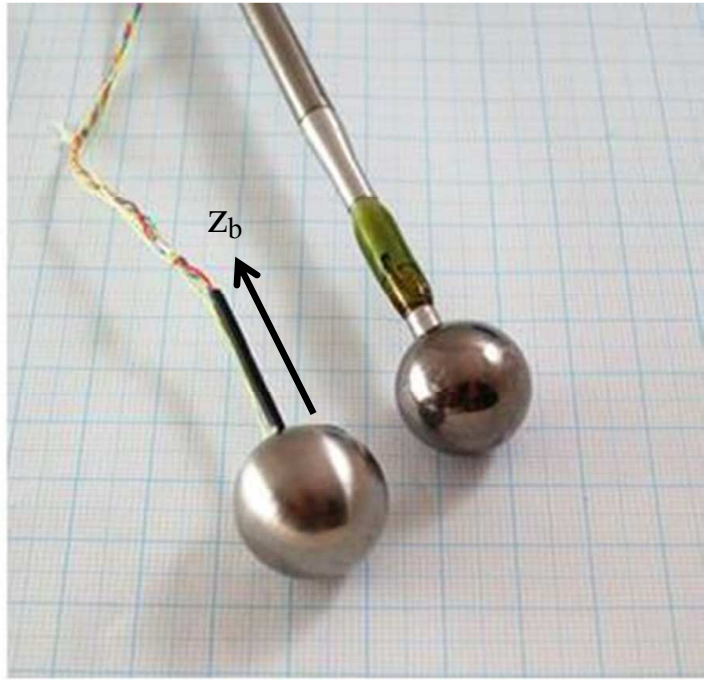

(b)

Figure 4. Model instrumented sphere shown: (a) during fabrication showing the void in the sphere for the tri-axis MEMS accelerometer (b) after fabrication alongside a centrifuge scale 'push-in' ball penetrometer

\section{Instrumented free-fall sphere}

The $20 \mathrm{~mm}$ diameter stainless steel sphere used for the free-fall centrifuge experiments (see Figure 4) had a mass of 31 grams. The centrifuge tests were conducted at $12.5 \mathrm{~g}$, such that the centrifuge model sphere is equivalent to the $250 \mathrm{~mm}$ sphere used in the field trials referred to previously and shown in Figure 3. The model sphere was instrumented with a tri-axis ADXL377 +/- $200 \mathrm{~g}$ MEMS accelerometer, measuring approximately $5 \times 5 \times 2 \mathrm{~mm}$. A commercially-available $\pm 200 \mathrm{~g}$ accelerometer was chosen as the only device offering three- 
axis sensing within the size constraints, and providing an analogue output. The sensor was located within a cylindrical void in the sphere (see Figure 4a) that was subsequently filled with epoxy. The accelerometer was aligned with the body frame of the sphere as shown in Figure $4 \mathrm{a}$. The body frame is a reference frame with three orthogonal axes $x_{b}, y_{b}$ and $z_{b}$. Before release in the centrifuge tests, the sphere was oriented such that the $z_{b}$ axis was approximately parallel to the centripetal acceleration vector in the centrifuge. The accelerometer measures accelerations $A_{b x}, A_{b y}$ and $A_{b z}$ along the three orthogonal axes of the body reference frame. As discussed previously, these data are used to calculate the resultant acceleration, $\mathrm{A}_{\mathrm{r}}$ :

$$
A_{r}=\sqrt{A_{b x}^{2}+A_{b y}^{2}+A_{b z}^{2}}
$$

The linear acceleration, a, of the sphere then becomes:

$a=A_{r}-\omega^{2} r$

where $\omega$ is the angular velocity of the centrifuge and $\omega^{2} \mathrm{r}$ is the centripetal acceleration level at a distance, $r$, from the centrifuge's axis of rotation to the sphere location.

\section{Soil preparation technique}

The offshore clay samples were reconstituted by adding minimal amounts of water to reconstitute the soils as slurries, and the kaolin clay sample was prepared by mixing kaolin powder with water to form a slurry at a moisture content of $120 \%$. The slurries were then mixed continuously for about 24 hours and then transferred to sample boxes, each with internal dimensions $598 \mathrm{~mm}$ long, $117 \mathrm{~mm}$ wide and $300 \mathrm{~mm}$ deep. These three sample boxes were then nested side by side in a larger strongbox to allow 'in-flight' consolidation of the three samples at the same time. The acceleration field acts radially in the centrifuge, therefore, the testing was performed only with the sample located along the longitudinal centreline of the beam centrifuge strongbox. Using three narrower internal sample boxes 
facilitated a greater test plan area by interchanging the sample boxes to put the 'test box' in the middle.

A $10 \mathrm{~mm}$ layer of sand was placed at the base of each box (i.e. before pouring the slurry) and the end walls of each box were then lined with a drainage blanket to ensure that there was no hydraulic gradient between the top and base of the sample. The samples were normally consolidated under self-weight consolidation in the centrifuge at $12.5 \mathrm{~g}$ for approximately 14 days, during which time a $30 \mathrm{~mm}$ water layer was maintained at the sample surface to ensure saturation. After consolidation, the surface of each soil sample was scraped to create a slightly overconsolidated soil with a level surface and final sample heights of $225 \mathrm{~mm}$ for the kaolin and West Africa Clay and $160 \mathrm{~mm}$ for the Laminaria clay.

\section{Centrifuge test details and procedures}

The centrifuge test programme in each sample comprised two free-fall sphere tests and one constant rate of penetration ball penetrometer test to determine the reference undrained shear strength. A minimum of 3 sphere diameters was allowed between rigid sample box walls and adjacent test sites to minimise potential boundary effects.

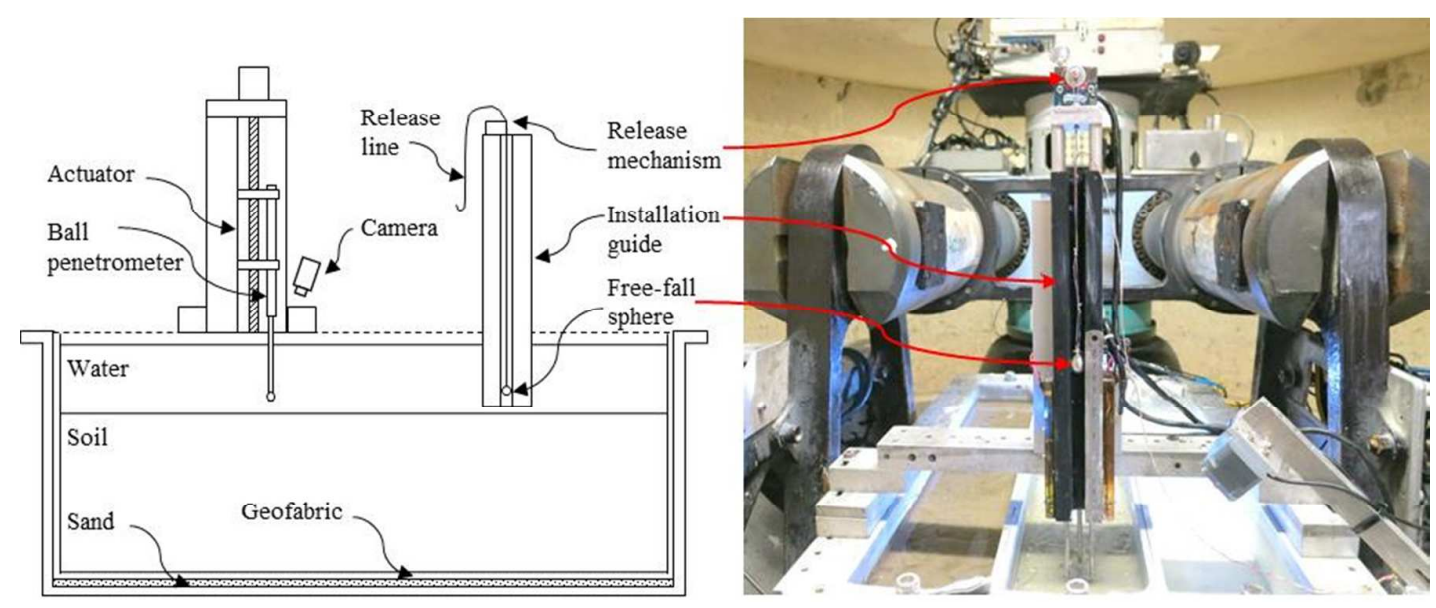

Figure 5. Experimental arrangement for the push-in ball penetrometer tests and instrumented free-fall sphere tests 
The experimental arrangement is shown in Figure 5. The vertical installation guide was located along the centreline of the strongbox with the exit located $2 \mathrm{~mm}$ above the sample surface. Prior to each free-fall test, the sphere was located in the installation guide at a height between 50 and $110 \mathrm{~mm}$ above the soil surface and the water level was increased to ensure that the sphere was fully submerged at the release height. A release cord attached to the top of the sphere kept the sphere at the preselected release height in the guide. The centrifuge was then spun up to $12.5 \mathrm{~g}$, and after a reconsolidation period of one hour, the sphere was released in-flight by supplying current to a resistor causing it to heat and burn through the release cord. The data during the release and embedment were acquired at $50 \mathrm{kHz}$ using the high speed logging mode of the data acquisition system (Gaudin et al. 2009).

\section{Test Results and Discussion}

Penetrometer tests and soil properties

Strength characterisation tests were conducted in-flight, primarily using a ball penetrometer $18 \mathrm{~mm}$ in diameter located at the end of a $5 \mathrm{~mm}$ diameter shaft. The measured resistance was corrected for the unequal area due to the presence of the shaft. This correction was almost negligible for the ball penetrometer tests due to the very low probe/shaft area ratio $(0.07)$. The reference ball penetrometer tests were conducted at a penetration rate of $0.3 \mathrm{~mm} / \mathrm{s}$ in kaolin and $0.25 \mathrm{~mm} / \mathrm{s}$ in the natural soils. This gave a dimensionless velocity, $\mathrm{V}=\mathrm{vd} / \mathrm{c}_{\mathrm{v}} \sim 140$ (where $\mathrm{v}$ is the velocity, $\mathrm{d}$ is the ball diameter and $\mathrm{c}_{\mathrm{v}}$ is the vertical coefficient of consolidation in each soil type) ensuring that the response was undrained (Finnie and Randolph 1994; House et al. 2001; Chung et al. 2006). The values of $c_{v}$ were based on Rowe Cell data at a vertical effective stress, $\sigma_{\mathrm{v}}^{\prime}=6 \mathrm{kPa}$ (Richardson et al. 2009; Bienen et al. 2015; White, 2015), which is the average of the range of $\sigma^{\prime}{ }_{v}$ of interest in the free-fall tests (i.e. the 
vertical effective stress at half of the mean embedment depth achieved in the free-fall sphere tests). This gave $\mathrm{c}_{\mathrm{v}}=1.23 \mathrm{~m}^{2} / \mathrm{yr}$ for kaolin and $1 \mathrm{~m}^{2} / \mathrm{yr}$ for the Laminaria and West Africa clays. The plastic limit (PL) and liquid limit (LL) for each soil are: Laminaria clay PL $=41 \%$ and $\mathrm{LL}=89 \%$, West Africa clay $\mathrm{PL}=50 \%$ and $\mathrm{LL}=165 \%$ and kaolin clay $\mathrm{PL}=27 \%$ and $\mathrm{LL}=61 \%$.

The undrained shear strength, $\mathrm{s}_{\mathrm{u}}$, was derived from the net penetration resistance, $\mathrm{q}_{\text {net }} \mathrm{using}$ the commonly adopted bearing factor $\mathrm{N}_{\mathrm{c} \text {-deep }}=10.5$ once a full-flow mechanism was established. The net resistance is the measured penetration resistance corrected for pore pressure on the ball shoulder (at the $\mathrm{u}_{2}$ position) and overburden pressure effects (Chung and Randolph 2004), with an unequal area ratio of 0.08 . The full-flow mechanism was observed when video capture of the penetrometer tests showed that the conical cavity created during shallow penetration closed over the top of the ball. In the kaolin, Laminaria and the West Africa soils, a normalised cavity depth of $0,1.7$ and 2 was observed, corresponding to a $\widehat{\mathrm{w}}_{\text {deep-op }}$ of $0,2.2$ and 2.5 respectively. At shallower penetration depths, the net penetration resistance was interpreted within the shallow penetration framework proposed by Morton et al. (2014). The resulting $s_{u}$ profiles are shown in Figure 6a using operative rather than invert depth (White et al. 2010; Morton et al. 2014). The increase in $s_{u}$ due to the soil scrape may be described using the well-known dependence of soil strength on overconsolidation ratio formula (Ladd et al. 1977):

$\mathrm{s}_{\mathrm{u}}=\sigma_{\mathrm{v}}^{\prime}\left(\frac{\mathrm{s}_{\mathrm{u}}}{\sigma_{\mathrm{v}}^{\prime}}\right)_{\mathrm{nc}} \mathrm{OCR}^{m}$

where $\sigma_{v}^{\prime}$ is the current vertical effective stress, determined from the $\gamma^{\prime}$ profile with depth (shown alongside the moisture content (w) profiles with depth in Figure 6b) and the slightly varying acceleration level with radius within the centrifuge (12.5 to $13.7 \mathrm{~g}$ over the depth of 
penetration in soil) and $\mathrm{m}$ is the plastic volumetric strain ratio (Schofield and Wroth 1968) taken as $\mathrm{m}=0.8$.
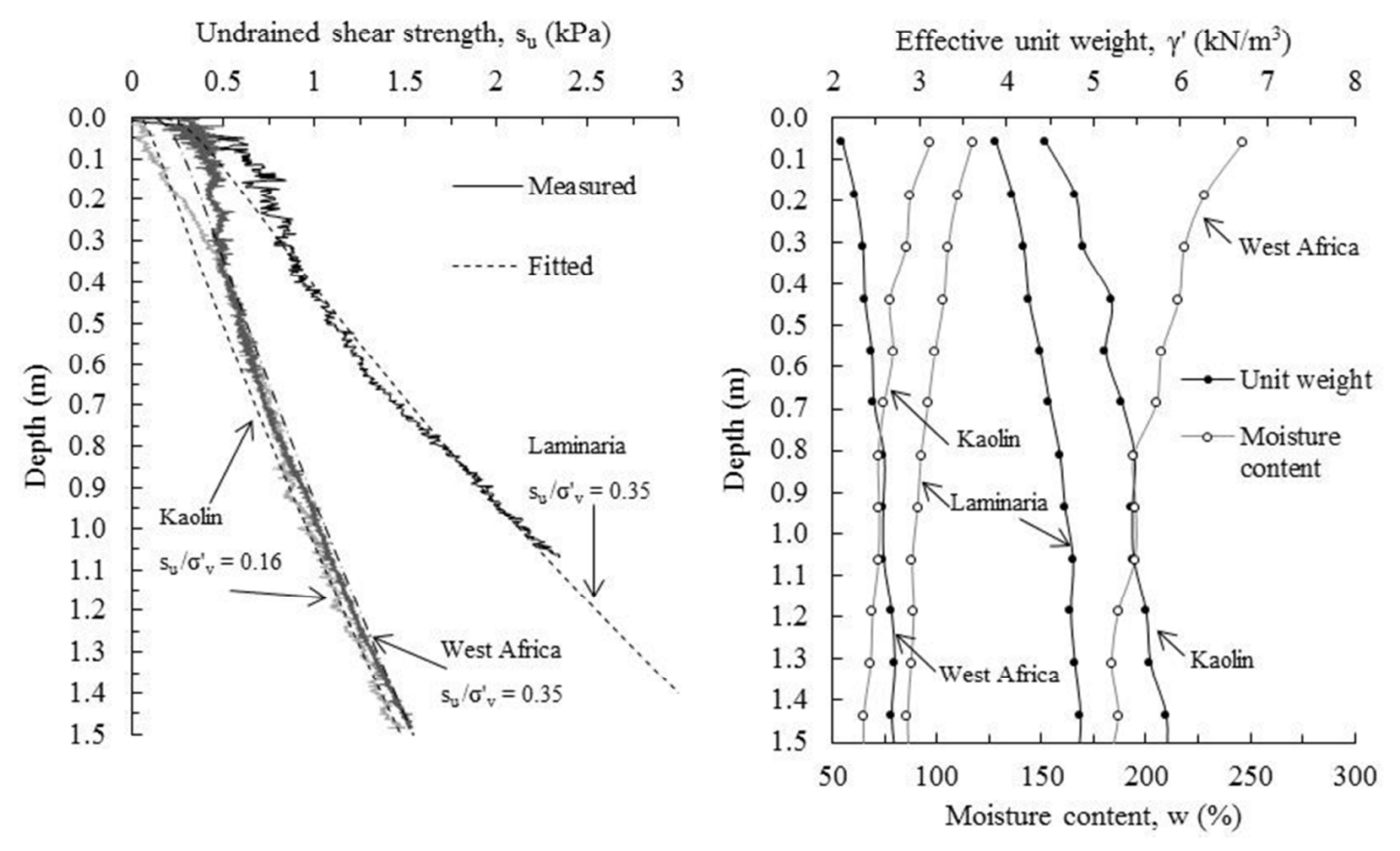

Figure 6. Profiles of: (a) undrained shear strength with depth (from ball penetrometer tests) and (b) moisture content and effective unit weight with depth established from post-testing sample cores

The undrained strength ratio, $\mathrm{s}_{\mathrm{u}} / \sigma_{\mathrm{v}}^{\prime}$, for each soil type is also shown on Figure $6 \mathrm{a}$. For kaolin clay $\mathrm{s}_{\mathrm{u}} / \sigma_{\mathrm{v}}^{\prime}=0.16$, equivalent to an undrained strength gradient with prototype depth, $\mathrm{k}=1$ $\mathrm{kPa} / \mathrm{m}$, which is typical for normally consolidated centrifuge samples of UWA kaolin clay (Chow et al. 2014; Morton et al. 2014; Hu et al. 2014). The Laminaria and West Africa $\mathrm{s}_{\mathrm{u}}$ profiles can both be represented by $\mathrm{s}_{\mathrm{u}} / \sigma_{\mathrm{v}}^{\prime}=0.35$, equivalent to $\mathrm{k}=2.2$ and $1.1 \mathrm{kPa} / \mathrm{m}$ for 
Laminaria and West Africa clay respectively owing to the different effective unit weight profile for the two soils (see Figure 6b).

Free-fall tests

A typical acceleration time history from a free-fall sphere test in kaolin clay is shown in Figure 7 together with the resulting velocities and displacements established from numerical integration of the acceleration data. The resultant acceleration, $A_{r}$, contains a component of the centripetal acceleration at the current sphere location. $\mathrm{A}_{\mathrm{r}}$ is therefore $\sim 11.9 \mathrm{~g}$ before release and slightly higher at $\sim 13 \mathrm{~g}$ after the sphere has come to rest in the soil at a larger radius from the centrifuge axis. These acceleration levels are consistent with the centripetal acceleration calculated at the sphere release height and embedment depth. The velocity and displacement data were obtained by numerically integrating the linear acceleration of the sphere, a (given by Equation 12), relative to the soil surface, once for velocity and twice for displacement. Following the logic outlined by O'Loughlin et al. (2014), the integration sequence has been performed in reverse from the end of the test when the sphere is embedded in the soil and the linear acceleration is zero (O'Loughlin et al. 2014). The acceleration trace on Figure 7 is characterised by a reduction in acceleration at the release height as the sphere begins to 'free-fall'. The acceleration does not reach zero due to frictional resistance between the sphere and the walls of the guide, and drag resistance on the sphere as it travels through the water. Oscillations in the acceleration trace during the free-fall stage are attributed to sporadic knocking of the sphere against the guide walls. At approximately $t=0.05 \mathrm{~s}$ the sphere impacts the soil with a velocity, $\mathrm{v}=2.8 \mathrm{~m} / \mathrm{s}$. The low resistance afforded by the soil at shallow embedment allows the sphere to continue to accelerate, reaching a peak velocity, $\mathrm{v}=$ $3.4 \mathrm{~m} / \mathrm{s}$ at $\mathrm{t}=0.065 \mathrm{~s}$ and a sphere invert embedment, $\mathrm{z}=48 \mathrm{~mm}$ (measured from the soil surface). The sphere comes to rest in the soil at $\mathrm{t}=0.118 \mathrm{~s}$, evident as when the acceleration returns to the centripetal acceleration, which causes the velocity to become zero and the 
displacement to reach a constant value. The point of impact with the soil surface can be difficult to establish from the acceleration trace alone, particularly for impact with soft soils. As outlined by O'Loughlin et al. (2014), integrating linear acceleration in reverse from the end of the test allows the velocity and displacement to be calculated incrementally. Impact with the soil surface can then be established as the point at which the calculated displacement equals the direct measurement of the embedment depth (obtained after the test when the centrifuge was at rest). In this example the final sphere embedment depth was $128 \mathrm{~mm}$, equivalent to over 6 diameters and the sphere orientation changed $4^{\circ}$ and $15^{\circ}$ in the $\mathrm{X}_{\mathrm{b}}$ and $\mathrm{Y}_{\mathrm{b}}$ axes (i.e. perpendicular to gravity) as it penetrated the water column and soil. This level of sphere spin indicates the sphere spin during soil penetration is not significant.

The acceleration spike evident in Figure 7 at $t=0.055 \mathrm{~s}$, just after impact with the soil surface, is noteworthy. This is thought to be the compression wave caused from the initial impact, travelling back past the sphere after reflection from the rigid sample boundary, an artefact of conducting the tests in a laboratory that would not be present in the field. Consideration of the time from initial impact to the apparent point of reflection on Figure 7, and the depth from the soil surface to the base of the sample, indicate that the wave is travelling at approximately $100 \mathrm{~m} / \mathrm{s}$, which is consistent with the speed of $\mathrm{P}$ wave propagation in soft soils. Similar observations have been made from $1 \mathrm{~g}$ free-fall penetrometer tests in uniform strength kaolin clay (Chow, 2012). Although the reflected wave does not appear to significantly affect the calculated velocity or displacement, it manifests as an increase in resistance and has therefore been excluded in the subsequent interpretation. 


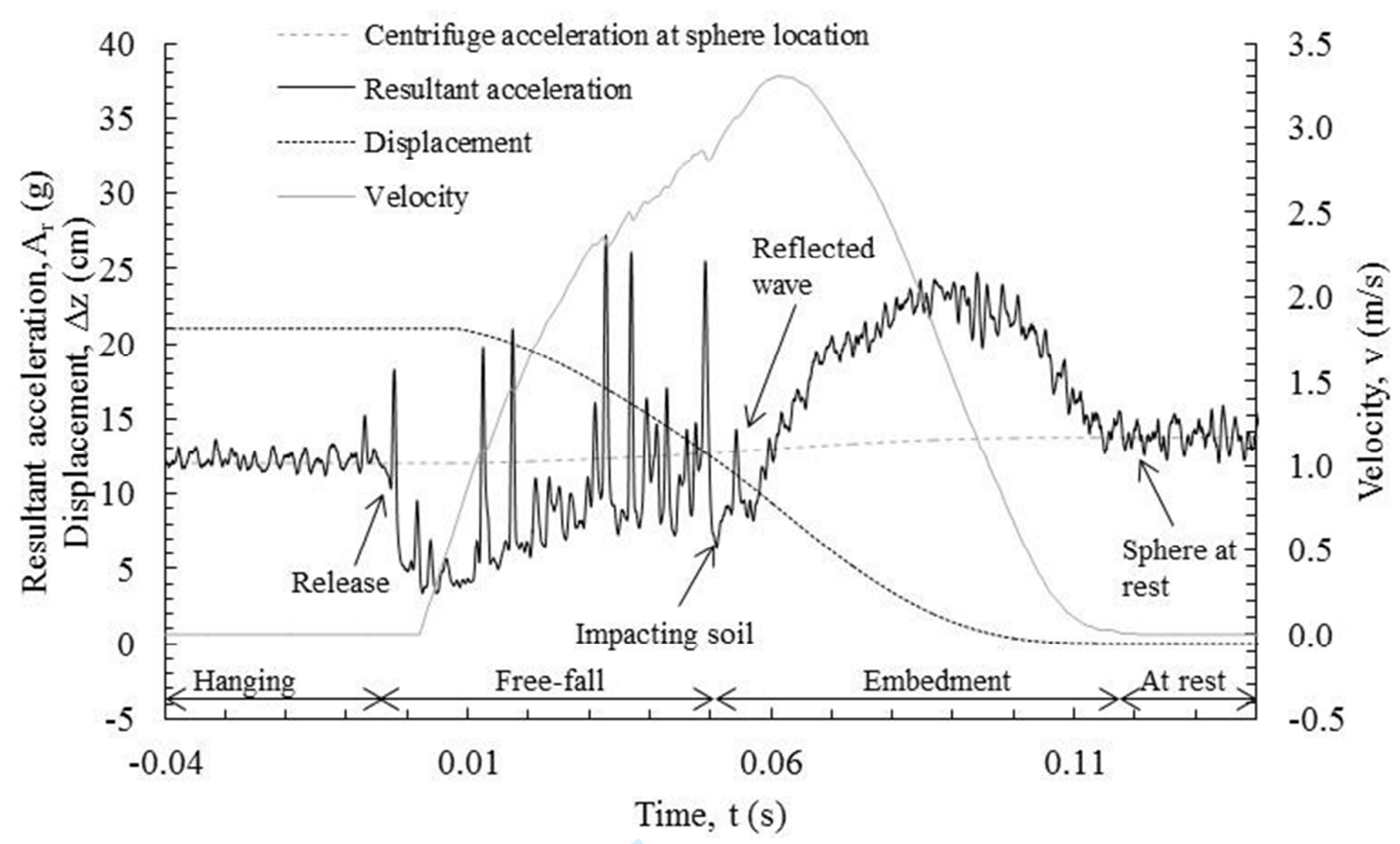

Figure 7: Accelerometer, velocity and displacement traces in a typical free-fall sphere centrifuge test in kaolin clay

Figure 8 shows time histories of the acceleration, velocity and displacement for typical tests in each soil type. Unlike Figure 7 in which the acceleration includes both the centripetal acceleration and the acceleration associated with the motion of the sphere, Figure 8 plots linear acceleration, a. Determined using Equation 12, a, is the sphere acceleration relative to the centripetal acceleration at the current sphere position within the rotating frame of reference. Therefore, the sphere acceleration is zero before release, changing abruptly to about $8 \mathrm{~g}$ immediately after release (consistent with the centripetal acceleration at the sphere release height) and zero when the sphere has come to rest in the soil.

Velocity and displacement traces derived from the linear acceleration data are provided in Figure $8 \mathrm{~b}$ and Figure $8 \mathrm{c}$ respectively. 

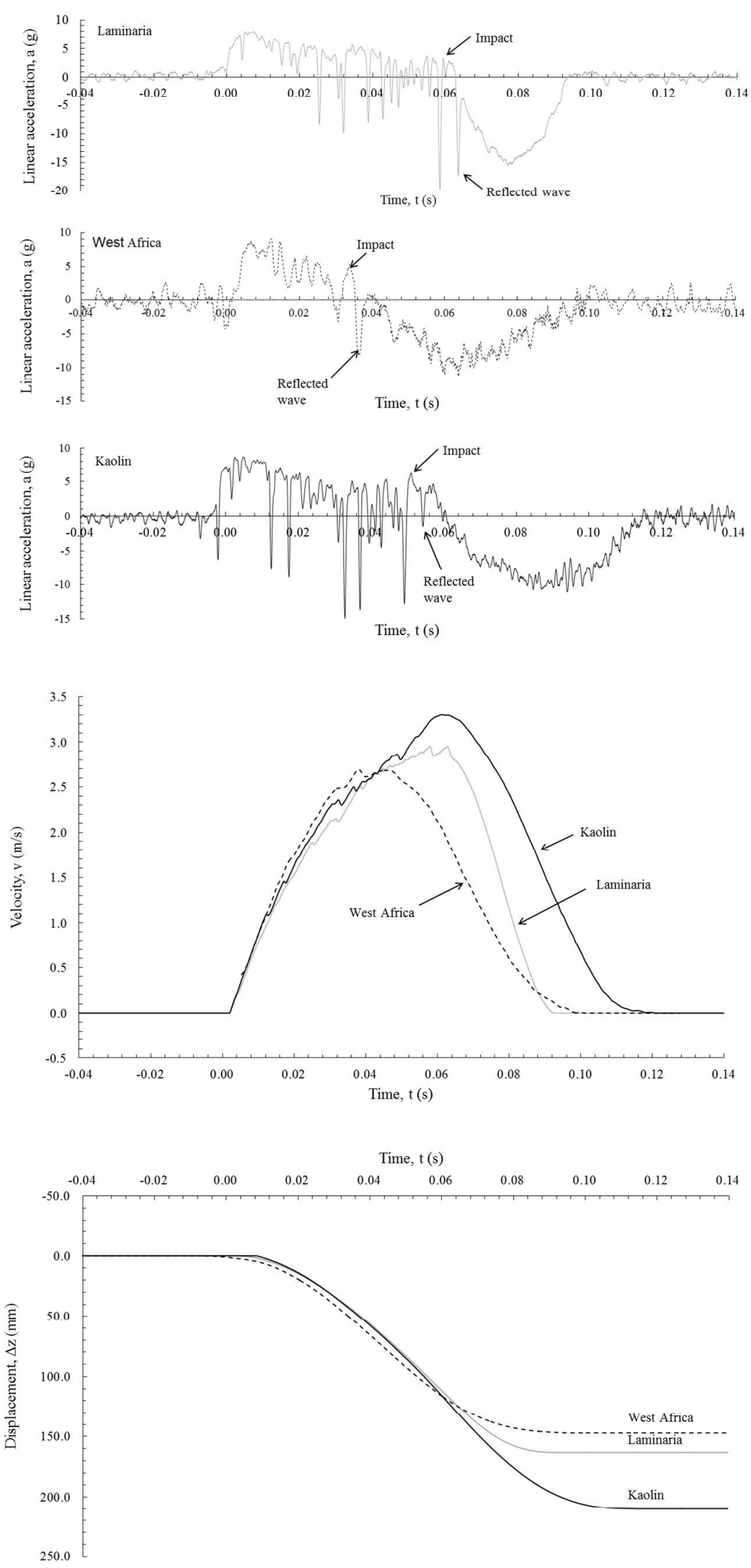
Figure 8: Example time histories of: (a) linear acceleration, (b) velocity and (c) displacement for the three soil types

As discussed earlier in the paper, the measurement approach is based on the vertical trajectory followed by the sphere during free-fall in water and embedment in soil. As shown by Figure 5, the vertical installation guide located above the centreline of the soil sample ensured that the sphere fell vertically in water. The guide applied the tangential force needed to keep the sphere rotating at the same angular velocity as the centrifuge, which requires an increasing tangential velocity with increasing radius.

Once the sphere is embedded in the soil, this force must be applied by the soil and there may be a tendency for the sphere to follow a curved trajectory through the soil, particularly for softer soil (O'Loughlin et al. 2014). This was checked in a number of tests by sectioning the soil sample after the test to reveal the final location of the sphere relative to the point of impact. An example (from a test in Laminaria clay) illustrating this process is provided in Figure 9, where it can be seen that the lateral displacement of the sphere was approximately 4 $\mathrm{mm}$. For a typical sphere embedment of $100 \mathrm{~mm}$ (5 sphere diameters), a lateral displacement of $4 \mathrm{~mm}$ increases the distance travelled in the soil by less than $0.1 \mathrm{~mm}(0.1 \%$ error $)$ compared with the vertical penetration depth. This is sufficiently small to be considered negligible and ignored, effectively validating the measurement approach. 


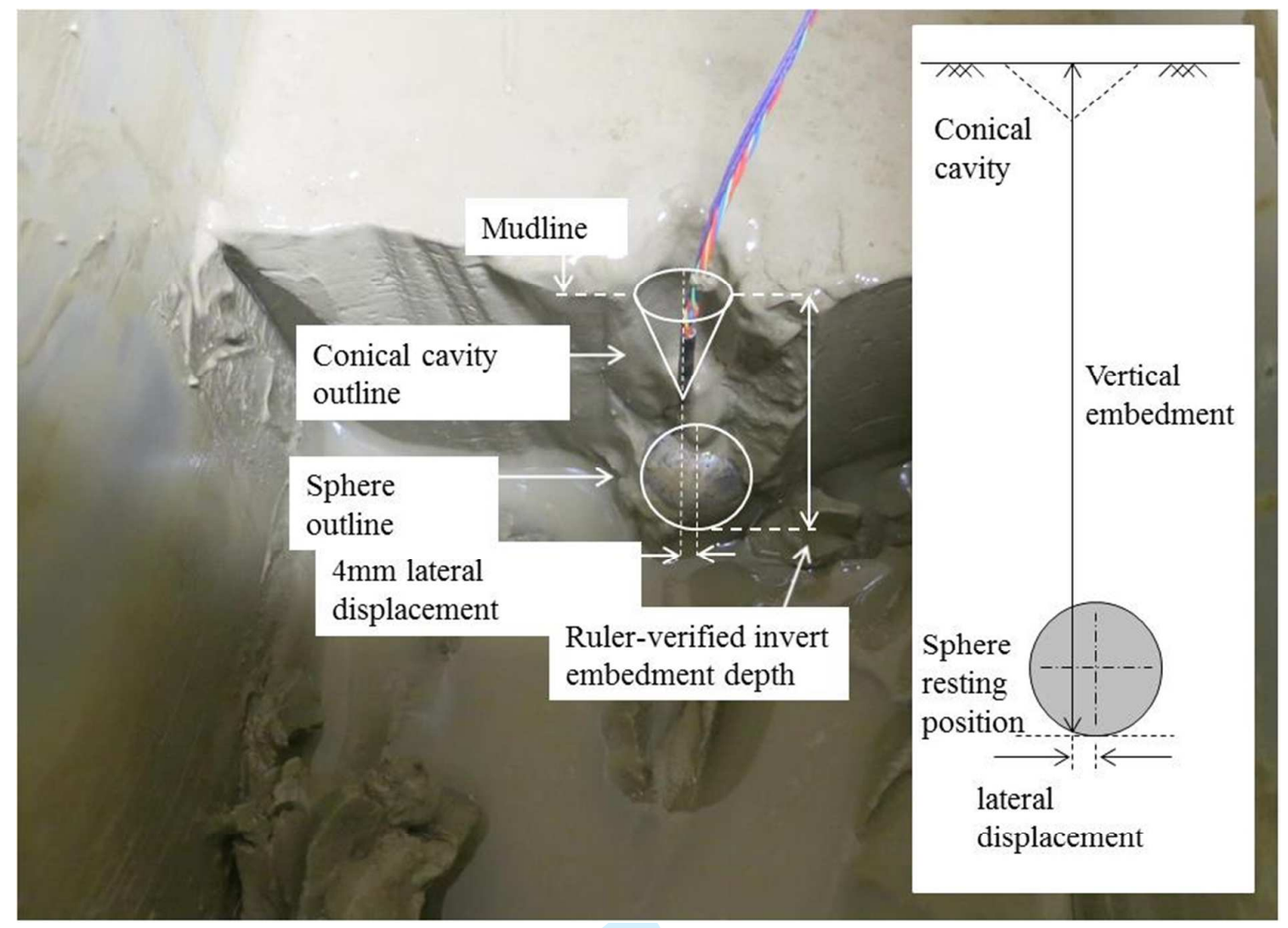

Figure 9: Post-test analysis of the sphere trajectory and measurement of the final embedment depth

\section{Interpretation of free-fall acceleration data}

The acceleration data are now considered within the simple framework outlined earlier in the paper that accounts for both geotechnical shearing resistance and fluid mechanics drag resistance. Rearranging Equation 7 allows $\mathrm{N}$ to be established as a function of $\mathrm{Re}_{\text {non-Newtonian }}$. This is shown on Figure 10a, 10b and 10c for the Laminaria, West Africa and kaolin clays respectively. The highest values of $\mathrm{Re}_{\text {non-Newtonian }}$ correspond with initial penetration, where the soil strength is low and the sphere velocity is high. Differences in the maximum $\operatorname{Re}_{\text {non- }}$ Newtonian values in Figure 10 reflect differences in strength and impact velocities between tests in each soil. At these high values of $\mathrm{Re}_{\text {non-Newtonian, }} \mathrm{N}$ is typically between 20 and 300,2 to 30 
times higher than the (geotechnical) bearing capacity factor, $\mathrm{N}_{c}$, emphasizing the importance of drag associated with this particular geometry. As penetration progresses, $\mathrm{Re}_{\text {non-Newtonian }}$ reduces as the soil strength increases (as reflected in Figure 6a) and the sphere velocity reduces. This has the effect of decreasing the dynamic resistance component, resulting in reducing values of $\mathrm{N}$. At deeper embedments, $\mathrm{N}$ approaches the limiting value of $\mathrm{N}_{\mathrm{c}}=10.5$ that was used at deep embedments to interpret the undrained shear strength from the net penetration resistance measured in ball penetrometer tests.

The data on Figure 10 require an assessment of the added mass force, $\mathrm{F}_{\mathrm{AM}}$, and the operative strength, $\mathrm{s}_{\mathrm{u}-\mathrm{op}}$. $\mathrm{F}_{\mathrm{AM}}$ was calculated using $\mathrm{C}_{\mathrm{m}}=0.5$, as established both theoretically and experimentally for a sphere (Sumer and Fredsoe 1997; Pantaleone and Messer, 2011). The operative strength, $\mathrm{s}_{\mathrm{u}-\mathrm{op}}$, which is reflected in both the vertical and horizontal axes of Figure 10, was calculated from Equation 5 using $\beta=0.07$, which approximates to an $18 \%$ change in soil strength per log cycle change in strain rate. 

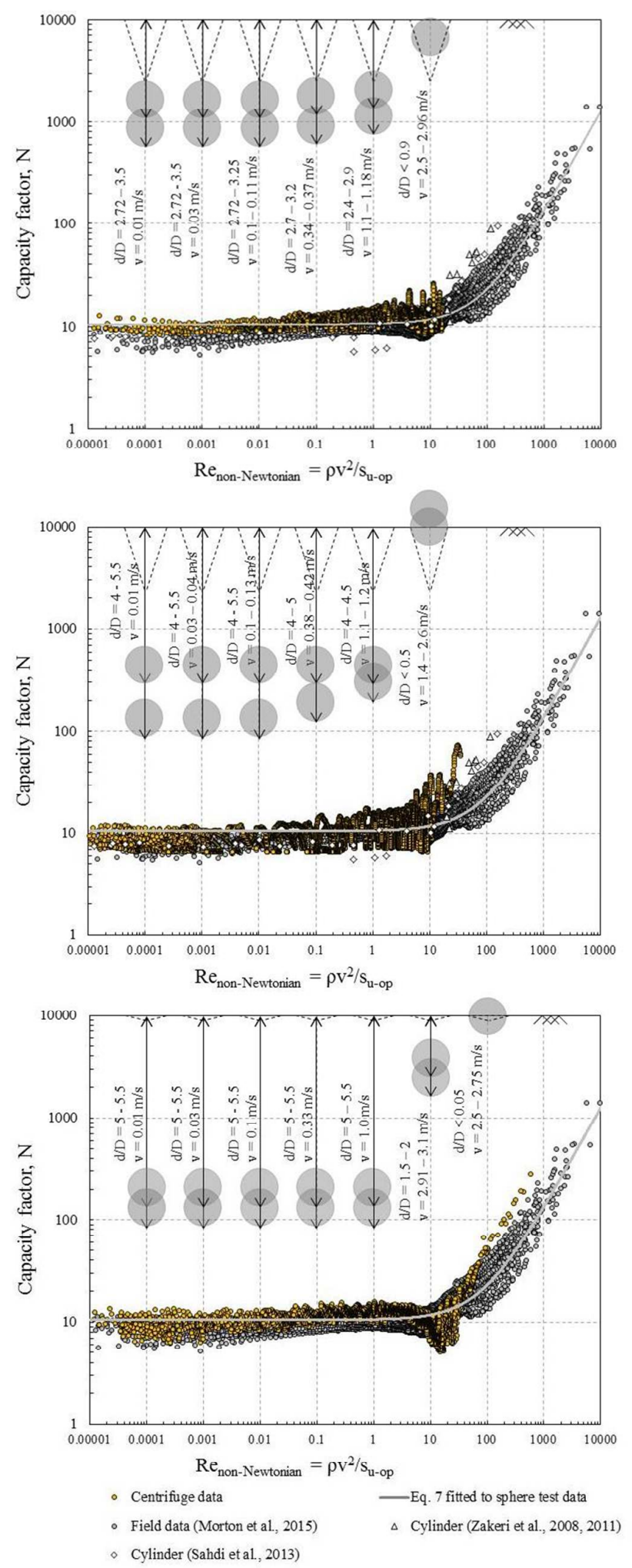

Figure 10: Relationship between $N$ and $\operatorname{Re}_{\text {non-Newtonian }}$ for a sphere in the three soil types: (a) Laminaria soil (b) West Africa clay (c) kaolin 
Also shown on Figure 10 are data from equivalent field experiments using the $0.25 \mathrm{~m}$ diameter free-fall sphere shown in Figure 2 in a soft lakebed (Morton et al. 2015) and equivalent data for a cylinder from experiments in a flume (Zakeri et al. 2008; Zakeri et al. 2011) and in a centrifuge (Sahdi et al. 2014). Collectively the data indicate that the threshold $\mathrm{Re}_{\text {non-Newtonian }}$ at which drag resistance dominates over soil strength is between 3 and 10 , similar to the range reported by Zhu and Randolph (2011), Randolph and White (2012) and Sahdi et al. (2014) for debris flow impacting on submarine piplelines. As indicated through the annotations on Figure 10, drag resistance dominates (at $\operatorname{Re}_{\text {non-Newtonian }}>3$ to 10 ) during shallow penetration at normalised embedment depths, $\mathrm{d} / \mathrm{D}<1$, at combinations of high velocities $(\mathrm{v}=2.5$ to $3.5 \mathrm{~m} / \mathrm{s})$ and low operative strengths $\left(\mathrm{s}_{\mathrm{u}-\mathrm{op}}=0\right.$ to $\left.0.5 \mathrm{kPa}\right)$. The centrifuge data can be described using Equation 7, which is also shown on Figure 10, using $\mathrm{N}_{\mathrm{c}}=10.5$ and $\mathrm{C}_{\mathrm{D}}=0.26$, where the latter was established from field tests reported by Morton et al. (2015). The centrifuge data eventually reach $\mathrm{N}=10.5$ at low $\mathrm{Re}_{\mathrm{Non}-\mathrm{Newtonian}}$, which is higher than $\mathrm{N}=8.5$ for the field data as this number was adopted in the interpretation of the piezoball data used as the measurement of $s_{u}$.

Within Figure 10, there is a small region $\left(10<\mathrm{Re}_{\text {non-Newtonian }}<30\right)$ that exhibits some lower values of $\mathrm{N}$. These correspond to very shallow embedments at which the bearing factor is reduced due to near-surface effects.

Figure 10 also indicates the post-analysed normalised cavity depth. In the kaolin clay sample the cavity depth was calculated as 0.1 diameters, such that soil flow around the advancing sphere occurred almost immediately, at very shallow depth. This is consistent with the very low dimensionless strength ratio, $\mathrm{s}_{\mathrm{u}} / \gamma^{\prime} \mathrm{D}=0.17$ at the transitional depth for kaolin clay, which leads to a calculated cavity depth, $\mathrm{d} / \mathrm{D}=0.1$ using Equation 9. In the Laminaria and West Africa clays the dimensionless strength ratios at the transition depth are similar $-\mathrm{s}_{\mathrm{u}} / \gamma^{\prime} \mathrm{D}=$ 0.97 and 0.94 respectively. Although the undrained strength profiles for the Laminaria and 
West Africa clays differs by a factor of approximately 2, the lower effective unit weight of the Laminaria clay results in almost identical dimensionless strength ratios for the two soils. Although this results in deeper cavities for the tests in Laminaria and West Africa clays, calculated using Equation 9 as $\widehat{\mathrm{w}}_{\text {deep-op }}=2.0$ and 2.3 for Laminaria and West Africa clay respectively. In both soils the sphere penetrated beyond the cavity depth such that a full-flow failure mechanism was established.

The merit of the framework is now explored by using the linear acceleration, described in Equation 12 to obtain $s_{u}$ profiles for each soil, based on the dynamic free fall data. In kaolin, a deeply embedment soil flow mechanism is assumed, such that the submerged weight of the sphere, $F_{S S}$, is the weight of the sphere in water minus the effective weight of the displaced soil, which may be calculated using the volume of the sphere. The capacity factor, N, may then be determined using Equation 7 with $\mathrm{N}_{\mathrm{c}}=10.5$ and $\mathrm{C}_{\mathrm{D}}=0.26$. As discussed in the previous section, $\mathrm{s}_{\mathrm{u}} / \gamma^{\prime} \mathrm{D}$ is higher in the West Africa and Laminaria clays at the final sphere embedment depth, which is sufficiently high that both the variation in $\mathrm{N}_{\mathrm{c}}$ with embedment depth and the soil buoyancy associated with the cavity formed by the penetrating sphere require consideration (Morton et al. 2014). The transitional embedment depth at which $\mathrm{N}_{\mathrm{c}}=$ $\mathrm{N}_{\mathrm{c} \text {-deep }}$, calculated using Equation 9, compared well to the post-analysed $\widehat{\mathrm{w}}_{\text {deep-op }}$ which were 2.2 and 2.5 for Laminaria and West Africa clay respectively and were within $10 \%$ of the calculated measurements. These transitional embedment depths allow the variation in $\mathrm{N}_{\mathrm{c}}$ with depth to be determined using Equation 8.

The resulting $\mathrm{s}_{\mathrm{u}}$ profiles obtained from Equation 10 are compared with the push-in ball penetrometer profiles in Figure 11 using operative rather than invert depth (White et al. 2010; Morton et al. 2014). Shallow embedment effects have been considered in the same way for the push-in tests as the free-fall tests. Interruptions to the $s_{u}$ profiles on Figure 11 correspond with the acceleration spikes observed in Figure 8 that are attributed to compression wave 
reflections and have been removed before conducting the inverse analysis. Figure 11 shows good agreement between the push-in and free-fall $s_{u}$ profiles, despite some disparity at very shallow embedment. The level of agreement observed on Figure 8 confirms the merit of the interpretation framework, which is made possible by the simple sphere geometry, and also to the potential of the free-fall sphere to be used as an effective tool for characterising the nearsurface strength of soft seabeds. As discussed previously, the framework extends the interpretation of a push-in ball penetrometer test using only two additional geotechnical parameters, $\mathrm{C}_{\mathrm{D}}$ and $\beta$.

The value of $\mathrm{C}_{\mathrm{D}}$ for a bluff body depends on the flow regime and the object geometry, as is well established in fluid mechanics. For a sphere, $C_{D}$ does not vary significantly over the range of non-Newtonian Reynolds numbers in Figure 10 where drag is significant (Schlichting et al. 2000). The consistent scatter around the trend line in Figure 10 indicates that a more refined approach with $C_{D}$ varying with $\mathrm{Re}_{\text {non-Newtonian }}$ would not capture the data set any better.

The range of $\beta$ reported in the literature is quite wide, spanning $\beta=0.05$ to 0.17 (Jeong et al. 2009), and a choice of $\beta$ is required in the interpretation of dynamic penetration problems. The wide reported range is partly due to different strain rate ranges being considered and a variety of test conditions, both in situ and in a laboratory. For instance, laboratory element tests involving variable strain rates tend to be at relatively low strain rates (typically $1 \% / \mathrm{h}$ or $2.8 \times 10^{-6} \mathrm{~s}^{-1}$; Boukpeti et al. 2012) and measure intact strength with no strength reduction from softening. In contrast, variable rate full-flow penetrometer tests usually involve strain rates in the range 0.2 to $20 \mathrm{~s}^{-1}$ and include compensating effects of strain softening that limit the strength increases associated with increasing strain rates. Free-fall sphere tests include a similar degree of strain softening to a variable rate full-flow penetrometer test. They also only involve slightly greater strain rates because the increased velocity is partly compensated by 
the larger diameter (maximum $v / D=31$ and $130 \mathrm{~s}^{-1}$ for field and centrifuge free fall ball tests respectively). Therefore, $\beta$ values for a free-fall sphere test should be guided by those measured in variable rate full-flow penetrometer tests, which typically give $\beta=0.05$ to 0.09 (Low et al. 2008; Chung et al. 2006). The effect of adjusting $\beta$ over this range is explored in Figure 12 for Laminaria clay. It is apparent that the lower bound $\beta=0.05$ corresponds with the largest departure from the base case profile established using $\beta=0.07$, although by less than $20 \%$. This uncertainty is comparable to the differences that are commonly linked to uncertainty between different laboratory strength tests (Bienen et al. 2010).
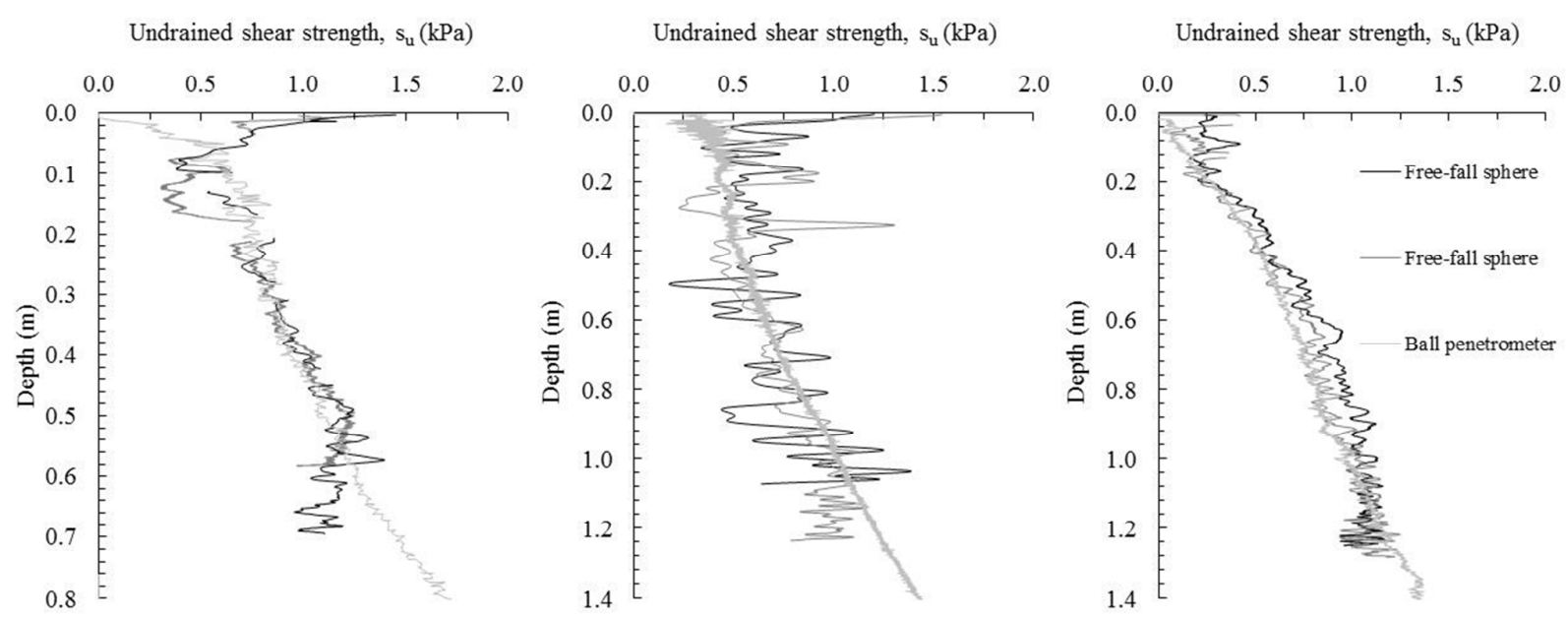

Figure 11: $s_{u}$ profiles from free-fall sphere and push-in penetrometer tests in: (a) Laminaria soil (b) West Africa soil (c) Kaolin 


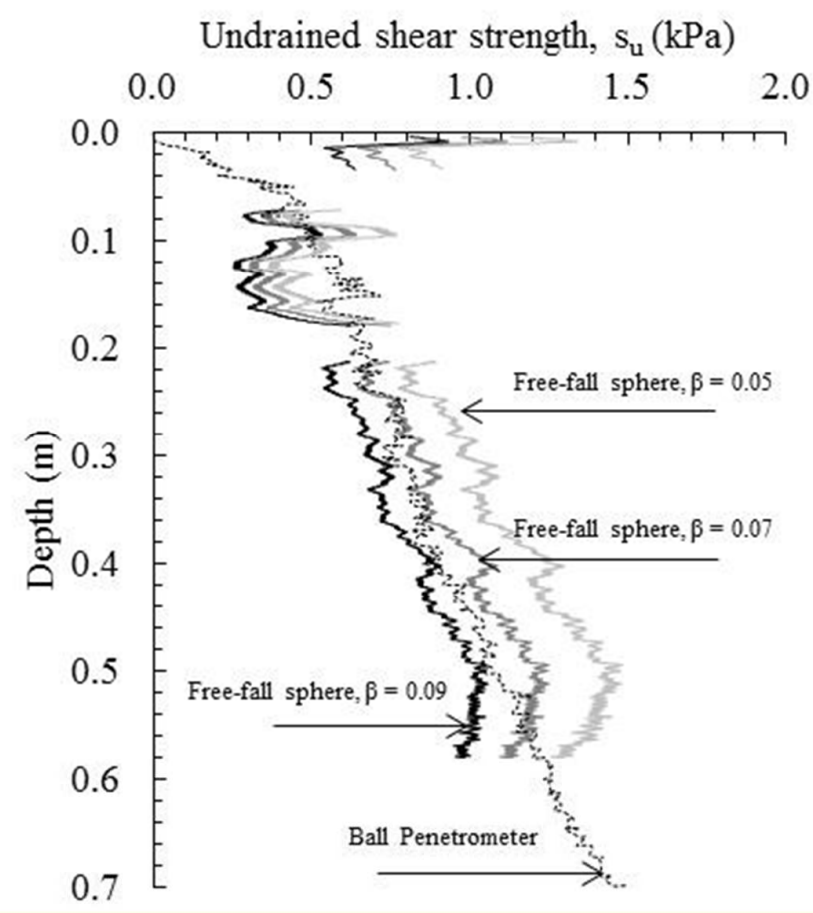

Figure 12: Effect of varying $\beta$ parameter on free-fall sphere $s_{u}$ profile

\section{Conclusion}

This paper has presented centrifuge tests undertaken to investigate the potential for a new in situ tool - the instrumented free-fall sphere - to measure the undrained shear strength profile of soft soil. The centrifuge experiments, which were conducted in kaolin clay and two reconstituted offshore clays, from Laminaria (Timor Sea) and West Africa (Gulf of Guinea) clay gave sphere embedments that were up to 5.5 diameters, which would provide strength measurements over the upper $1.5 \mathrm{~m}$ of the seabed for a practically-dimensioned field tool.

Interpretation of sphere acceleration measurements to quantify the soil strength relied on a framework cast in terms of both drag resistance and geotechnical shear resistance, but formulated in terms of a single capacity factor. This capacity factor reduces to the 
conventional geotechnical bearing capacity factor at low strain rates, but has been shown in these experiments to be over an order of magnitude larger when the sphere is penetrating at high velocities.

The merit of the simple framework was demonstrated through an inverse analysis in which the undrained shear strength was calculated from the measured acceleration data, accounting for buoyancy created by the passage of the advancing sphere and a reduced bearing capacity factor at shallow embedment. Good agreement was obtained between the dynamically measured $s_{u}$ profile and the $s_{u}$ profile measured during push-in ball penetrometer tests.

The level of agreement shown, and the relative insensitivity to the choice of strain rate parameter, suggests that the instrumented free-fall sphere is effective in characterising the near-surface strength of soft seabeds, and offers a complementary tool that we envisage could find utility in in situ testing practice.

\section{Acknowledgements}

This work forms part of the activities of the Centre for Offshore Foundation Systems (COFS), currently supported as a node of the Australian Research Council's Centre of Excellence for Geotechnical Science and Engineering (Grant no. CE110001009), and through the Fugro Chair in Geotechnics, the Lloyd's Register Foundation Chair and Centre of Excellence in Offshore Foundations and the Shell EMI Chair in Offshore Engineering (held by the third author). 


\section{References}

Bienen, B. Ragni, F., Cassidy. M.J., and Stanier, S.A. 2015. Effects of consolidation under a penetrating footing in carbonate silty clay. Journal of Geotechnical and Geoenvironmental Engineering, 04015040.

Bienen, B., Cassidy. M.J., Randolph, M.F. and Tel. K.L. 2010. Characterisation of undrained shear strength using statistical methods. 2nd International Symposium on Frontiers in Offshore Geotechnics, Perth, Australia. pp. 661-666.

Blake, A.P., O’Loughlin, C.D., Morton, J.P., O’Beirne, C., Gaudin, C. and White, D.J. 2015. In-situ measurement of the dynamic penetration of free-fall projectiles in soft soils using a low cost inertial measurement unit. ASTM Geotechnical Testing Journal. DOI: 10.1520/GTJ20140135.

Boukpeti, N., White, D.J., Randolph, M.F. and Low, H.E. 2012. Strength of fine-grained soils at the solid-fluid transition. Géotechnique 62(3): 213-226, http://dx.doi.org/10.1680/geot.9.P.069.

Chow, S.H., O’Loughlin, C.D., and Randolph, M.F. 2014. Soil strength estimation and pore pressure dissipation for free-fall piezocone in soft clay. Géotechnique 64(10): 817827, http://dx.doi.org/10.1680/geot.14.P.107.

Chow, S.H. 2012. Free falling penetrometer tests in clay. PhD. University of Sydney.

Chung, S.F., Randolph, M.F., and Schneider, J.A. 2006. Effect of penetration rate on penetrometer resistance in clay. Journal of Geotechnical and Geoenvironmental Engineering, 132(9): 1188-1196. 
Dayal, U., Allen, J., and Jones, J. 1975. Use of an impact penetrometer for the evaluation of the in-situ strength of marine sediments. Marine Georesources and Geotechnology,

Finnie, I.M.S., and Randolph, M.F. 1994. Punch-through and liquefaction induced failure of shallow foundations on calcareous sediments. Proceedings of the International Conference on behaviour of offshore structures, Boston, pp. 217-230.

Furlong, A., Osler, J., Christian, H., Cunningham, D and Pecknold, S. 2006. The Moving Vessel Profiler (MVP) - a rapid environmental assessment tool for the collection of water column profiles and sediment classification. Proceedings of Undersea Defence Technology Pacific Conference 2006, San Diego, US, pp. 1-13.

Gaudin, C., White, D.J., Boylan, N., Breen, J., Brown, T., De Catania, S. and Hortin, P. 2009. A wireless high-speed data acquisition system for geotechnical centrifuge model testing. Measurement Science and Technology, 20(9): 095709, http://dx.doi.org/10.1088/0957-0233/20/9/095709.

Hossain, M.S., Hu, Y., Randolph, M.F., and White, D.J. 2005. Limiting cavity depth for spudcan foundations penetrating clay. Géotechnique, 55(9), pp. $679-690$.

House, A.R., Oliveira, J.R.M.S., and Randolph, M.F. 2001. Evaluating the coefficient of consolidation using penetration tests. International Journal of Physical Modelling in Geotechnics, 1(3), pp. 17-25.

Jeanjean, P., Spikula, D., and Young, A. 2012. Technical vetting of free-fall cone penetrometer. Proceedings of 7 th international offshore site investigation and geotechnics conference: Integrated geotechnologies - present and future, pp. 15-18. London UK: Society for Underwater Technology. 
Jeong, S. W., Leroueil, S. and Locat, J. 2009. Applicability of power law for describing the rheology of soils of different origins and characteristics. Canadian Geotechnical Journal, 46, pp 1011-1023.

Ladd, C.C., Foot, R., Ishihara, K., Schlosser, F., and Poulos, H.G. (1977). Stress-deformation and strength characteristics. Proceedings of the 9th International Conference on Soil Mechanics and Foundation Engineering, Tokyo 2: 421-494.

Lamb, H. (1932). Hydrodynamics. Cambridge University Press.

Lehane, B.M., O'Loughlin, C.D., Gaudin, C., and Randolph, M.F. 2009. Rate effects on penetrometer resistance in kaolin. Géotechnique, 59(1): 41-52.

Low, H.E., Randolph, M.F., DeJong, J.T., and Yafrate, N. J. 2008. Variable rate full-flow penetration tests in intact and remoulded soil. Procceedings of the 3rd International Conference on Site Characterization, Taipei, 1087-1092.

Morton, J.P., and O'Loughlin, C.D. 2012. Dynamic penetration of a sphere in clay. In Proceedings of 7 th International Offshore Site Investigation and Geotechnics Conference: Integrated Geotechnologies - Present and Future, London, UK: Society for Underwater Technology, 223-230.

Morton, J.P., O’Loughlin, C.D. and White, D.J. 2014. Strength assessment during shallow penetration of a sphere in clay. Géotechnique Letters 4, October-December, 262-266.

Morton, J.P., O’Loughlin, C.D., and White, D.J. 2015. Estimation of soil strength by instrumented free-fall sphere tests. Géotechnique (under review). 
O'Loughlin, C.D., Gaudin, C., Morton, J.P., and White, D.J. 2014. MEMS accelerometers for measuring dynamic penetration events in geotechnical centrifuge tests. International Journal of Physical Modelling in Geotechnics 14(2), pp. 31-39.

O’Loughlin, C.D., Richardson, M.D., Randolph, M.F., and Gaudin, C. 2013. Penetration of dynamically installed anchors in clay. Géotechnique 63(11), pp. 909-919. http://dx.doi.org/10.1680/geot.11.P.137.

Pantaleone, J., and Messer, J. 2011. The added mass of a spherical projectile. American Journal of Physics, 79(12), pp. 1202-1210.

Richardson, M.D., O’Loughlin, C.D., and Randolph, M.F. 2009. Setup following installation of dynamic anchors in normally consolidated clay. Journal of Geotechnical and Geoenvironmental Engineering 135(4), pp. 487-496.

Sahdi, F., Gaudin, C., White, D.J., Boylan, N., and Randolph, M.F. 2014. Centrifuge modelling of active slide-pipeline loading in soft clay. Géotechnique, 64(1), pp. 1627. http://dx.doi.org/10.1680/geot.12.P.191.

Sabetamal H, Nazem M, Carter J, Sloan S. Large deformation dynamic analysis of saturated porous media with applications to penetration problems. Comput Geotech 2014;55:117-31.

Schlichting, H., Gersten, K., and Gersten, K. (2000). Boundary-layer theory. Springer Science \& Business Media.

Stark, N., Kopf, A., and Hanff, H. 2009. Geotechnical investigations of sandy seafloors using dynamic penetrometers. In Proceedings of OCEANS 2009, MTS/IEEE Biloxi Marine technology for our future: global and local challenges, pp. 1-10. New York, NY, USA: IEEE. 
Steiner, A., Kopf, A.J., L’Heureux, J., Kreiter, S., Stegmann, S., Haflidason, H., and Moerz, T. 2014. In situ dynamic piezocone penetrometer tests in natural clayey soils-a reappraisal of strain rate corrections. Canadian Geotechnical Journal, 51(3), pp. 272288.

Sumer, B. M., and Fredsoe, J. 1997. Hydrodynamics around cylindrical structures. World Scientific. Singapore.

Tho, K. K., Leung, C. F., Chow, Y. K. and Palmer, A. C. 2012. Deep cavity flow mechanism of pipe penetration in clay. Canadian Geotechnical Journal, 49(1), pp. 59-69.

White, D. J., Gaudin, C., Boylan, N., and Zhou, H. 2010. Interpretation of T-bar penetrometer tests at shallow embedment and in very soft soils. Canadian Geotechnical Journal, 47(2), pp. 218-229.

Young, A. G., Bernard, B. B., Remmes, B. D., Babb, L., and Brooks, J. M. 2011. CPT stinger - an innovative method to obtain CPT data for integrated geoscience studies. Proceedings of the offshore technology conference, Houston, TX, paper OTC 21569.

Zakeri, A., Hoeg, K., and Nadim, F. 2008. Submarine debris flow impact on pipelines - Part I: Experimental investigation. Coastal Engineering, 55(12), pp. 1209-1218.

Zakeri, A., Chi, K., and Hawlader, B. 2011. Centrifuge modelling of glide block and outrunner block impact on submarine pipelines. In Proceedings of the Offshore Technology Conference, Houston, Texas, USA, paper OTC 21256. 